\begin{tabular}{|c|c|c|}
\hline $\begin{array}{c}\text { ISSN 2525-4812 (versão online) } \\
\text { ISSN 2238-7641 (versão impressa) } \\
\text { http://www.revistaterceiramargem.com/ } \\
\text { index.php/terceiramargem/index }\end{array}$ & $\begin{array}{c}\text { Recebido em: 3/5/2019 } \\
\text { Aprovado em: 27/4/ } 2020 \\
\text { Período de publicação: jan., } 2021\end{array}$ & $\begin{array}{c}\text { Revista Terceira } \\
\text { Margem Amazônia } \\
(\text { v. } 6 \cdot \text { n. especial } 16 \cdot \text { Jan. } 2021 \text { ) }\end{array}$ \\
\hline
\end{tabular}

Como citar o artigo:

SILVA, L. J. S; MENEGHETTI, G. A; PINHEIRO, J. O. C. Elementos para a discussão sobre políticas e programas de preservação dos serviços ambientais no Amazonas. Revista Terceira Margem Amazônia. v. 6, n. especial 16, p. 85-104, 2021. DOI: http://dx.doi.org/10.36882/2525-4812.2021v6i16.ed.esp.p85-104

\title{
ELEMENTOS PARAA DISCUSSÃO SOBRE POLÍTICAS E PROGRAMAS DE PRESERVAÇÃO DOS SERVIÇOS AMBIENTAIS NO
} AMAZONAS

Lindomar de Jesus de Sousa Silva ${ }^{1}$ Gilmar Antonio Meneghetti ${ }^{2}$ José Olenilson da Costa Pinheiro ${ }^{3}$

\begin{abstract}
Resumo: O artigo faz uma breve reflexão sobre os desafios dos programas de serviços ambientais e ecossistêmicos no Amazonas. Para isso foi realizada uma pesquisa bibliográfica e exploratória. A pesquisa bibliográfica identificou produções científicas, relatórios e avaliações relacionadas a criação de Unidades de Conservação (UCs) e do Programa Bolsa Floresta (PBF), visando obter elementos para compreensão de potencialidade e limites à efetivação dessas políticas. A pesquisa exploratória foi realizada no âmbito do Projeto Mapeamento de Castanhais Nativos e Caracterização Socioambiental e Econômica de Sistemas de Produção da Castanha-do-Brasil na Amazônia (MapCast), na Reserva de Desenvolvimento Sustentável Piagaçu-Purus, Beruri, AM. Essa pesquisa visa identificar os limites socioeconômicos relacionados aos sistemas extrativistas e produtivos e como esses aspectos influenciam na efetivação de ações voltadas a conservação e manutenção dos serviços ambientais e ecossistêmicos. A pesquisa mostra que as ações de criação das UCs e do PBF foram positivas porque evidenciam o papel dos extrativistas na conservação florestal e o avanço das estratégias e políticas de serviços ambientais. Entretanto, consideramos que há a necessidade de ações voltadas a ampliar o papel de comunidades e extrativistas transformando-os em sujeitos sociopolíticos, ou seja, agentes com ampla habilidade para definir e implementar ações voltadas ao desenvolvimento. As ações precisam englobar as diversas dimensões da vida humana e ambiental, políticas públicas de saúde, educação, moradia e outras, como também mostrar a necessidade de aprimorarmos os sistemas produtivos extrativos e agrícolas das comunidades, como meio de impulsionar o bem-estar individual e comunitário. Sem tais políticas e ações quaisquer medidas, projetos e programas tornam-se incompletos.
\end{abstract}

Palavras-chave: serviços ambientais, comunidades, sistemas de produção, Amazônia.

\footnotetext{
Sociólogo, D. Sc. em Desenvolvimento Sustentável do Trópico Úmido, pesquisador da Embrapa Amazônia Ocidental, Manaus, AM. E-mail: lindomar.j.silva@embrapa.br

(D) https://orcid.org/0000-0002-4816-486X

2 Engenheiro-agrônomo, M. Sc. em Desenvolvimento Agricultura e Sociedade, pesquisador da Embrapa Amazônia Ocidental, Manaus, AM. E-mail: gilmar.meneghetti@embrapa.br

(D) https://orcid.org/0000-0001-5645-8916

3 Economista, M. Sc. em Agriculturas Familiares e Desenvolvimento Sustentável, pesquisador da Embrapa Amazônia Ocidental, Manaus, AM. E-mail: jose.pinheiro@embrapa.br

(iD https://orcid.org/0000-0003-0036-6646
} 


\title{
ELEMENTS FOR DISCUSSION ON POLICIES AND PROGRAMS FOR THE PRESERVATION OF ENVIRONMENTAL SERVICES IN AMAZONAS
}

\begin{abstract}
The article briefly reflects on the challenges of environmental and ecosystem service programs in Amazonas. For this, a bibliographic and exploratory research was carried out. The bibliographic research identified the scientific productions, reports and evaluations related to the creation of Conservation Units (UC) and the Bolsa Floresta Program, aiming to obtain elements to understand the potential and limits to the effectiveness of policies. The exploratory research was carried out within the scope of the project Mapping Native Chestnuts and Socio-Environmental and Economic Characterization of Brazil Nut Production Systems in the Amazon (MapCast), in the Piagaçu - Purus Sustainable Development Reserve, in Beruri - AM. This research aims to identify the socioeconomic limits related to extractive and productive systems, and how these aspects influence the implementation of actions aimed at the conservation and maintenance of environmental and ecosystem services. The research shows that the creation actions of the Conservation Units (UC) and the Bolsa Floresta Program (PBF) were positive because they highlight the role of extractivists in forest conservation and the advancement of strategies and policies for environmental services. However, we consider that there is a need for actions aimed at expanding the role of communities and extractivists, transforming them into socio-political subjects, that is, agents with ample ability to define and implement actions aimed at development. Actions need to encompass the different dimensions of human and environmental life, public health, education, housing and other policies, as well as showing the need to improve the communities' extractive and agricultural production systems, as a means of boosting individual and Community level. Without such policies and actions, any measures, projects and programs are incomplete.
\end{abstract}

Key words: environmental services, communities, Production Systems, Amazon.

\section{Introdução}

A discussão sobre a conservação do ambiente remonta ao período pós-segunda guerra e se intensifica a partir dos anos setenta. Um dos desdobramentos dessa discussão, e que envolve também a economia na discussão, são os serviços ambientais e agroecossistêmicos, que a natureza presta gratuitamente para a humanidade, mas exige contrapartidas da sociedade e dos beneficiários desses serviços, sob pena de colocar em risco a sua continuidade.

No Brasil e no mundo há comunidades e populações cujo modo de vida e ambiente em que vivem dependem essencialmente dos serviços ambientais e ecossistêmicos. É o caso das comunidades indígenas e das comunidades ribeirinhas que vivem em reservas extrativistas no Amazonas e que dependem da floresta e dos seus serviços para viver. Entretanto, os beneficiários desses serviços têm como obrigação a conservação dos recursos naturais. Ao mesmo tempo necessitam gerar renda e segurança alimentar por meio dos serviços e do desenvolvimento das atividades em suas pequenas áreas de produção agrícola.

A preservação dos serviços, do modo de vida e, ao mesmo tempo, a garantia de condições dignas de vida às famílias são os desafios que se colocam à sociedade e às políticas de preservação, pois mostraram-se insustentáveis ao longo do tempo, sem um aparato legal e de política de apoio. As políticas públicas são fundamentais para a preservação do ambiente e seus serviços e para assegurar condições dignas às pessoas. 
Por meio de pesquisa bibliográfica, o texto apresenta um embasamento teórico de conceitos e definições sobre os serviços ambientais e agroecossistêmicos mediante pesquisas de diversos autores, com focos de abordagens diversas e complementares. Entre as abordagens e reflexões relacionadas ao meio ambiente está a Avaliação Ecossistêmica do Milênio, realizada pela Organização das Nações Unidas (ONU), que aborda de forma consistente, entre outras coisas, a perda de espécies da biodiversidade e a redução de serviços ecossistêmicos ao longo do tempo. Esse relatório também classifica os serviços ambientais em quatro categorias: serviços de provisão, regulação, culturais e de suporte, explicitando o significado de cada um deles, conforme os benefícios que as pessoas recebem dos serviços ecossistêmicos (MA, 2005, p. V).

As políticas de apoio aos serviços ambientais precisam estar amparadas a legislações que permitam a sua execução. $\mathrm{O}$ artigo faz uma abordagem das legislações federal e estadual que dão suporte à implantação das políticas de preservação e acesso aos serviços ambientais e ecossistêmicos no Amazonas. Observa-se que a Lei Federal no 312/15 que respalda a política de serviços ambientais é posterior à lei estadual do Amazonas. A legislação estadual do Amazonas é mais ampla e estabelece, por meio da Lei $n^{0} 3.135 / 2007$ (BRASIL, 2007), a Política Estadual sobre Mudanças Climáticas, Conservação e Desenvolvimento Sustentável do Amazonas (PEMC-AM). Essa legislação permite a criação de programas de apoio aos serviços ambientais e ecossistêmicos, como o Programa Bolsa Floresta, que é um instrumento de apoio à manutenção dos serviços.

A pesquisa, cujos resultados estão sendo apresentados, foi desenvolvida na Unidade de Conservação da Reserva de Desenvolvimento Sustentável de Piaguçu Purus (RDS-PP), nas comunidades Divino Espírito Santo (Pinheiro), Nossa Senhora do Livramento (Uixi), São João Batista (Uauaçu), em Beruri, AM. Essa pesquisa tem caráter qualitativo. A pesquisa bibliográfica identificou elementos dos programas e ações de serviços ambientais desenvolvidos no âmbito do governo estadual, em 2007, como incentivo à implantação das Unidades de Conservação Estadual, que atualmente ocupam 12,6 \% do território estadual, e do Programa Bolsa Floresta. A pesquisa bibliográfica buscou elementos para análise do estágio atual dos serviços ambientais decorrentes de ações governamentais e instituições privadas no estado. A pesquisa exploratória, desenvolvida por meio de entrevistas a agricultores/extrativistas das comunidades mencionadas, permitiu entender a dinâmica socioeconômica do sistema de produção das comunidades rurais da RDS-PP, e com esses elementos será possível pensar a construção do conhecimento e o processo de transferência de tecnologia e inovação para essas comunidades.

O objetivo da pesquisa era identificar elementos e impactos da implantação da política e programa de apoio aos serviços ambientais e ecossistêmicos em quatro comunidades da RDS-PP, analisando potencialidades e limites à efetivação delas. Buscou-se identificar os limites socioeconômicos das famílias e dos sistemas de produção extrativistas e agrícolas locais e entender como esses aspectos influenciam a efetivação de ações voltadas à conservação e manutenção dos serviços ambientais e ecossistêmicos. O entendimento dos limites socioeconômicos dos sistemas possibilita a construção do conhecimento e permite estabelecer um processo de transferência de tecnologia e inovação para essas comunidades. 


\section{Metodologia}

O artigo é resultado de pesquisa bibliográfica e exploratória, de natureza qualitativa. A pesquisa bibliográfica analisou textos, artigos, relatórios e outros documentos relacionados às políticas de serviços ambientais implementados pelo estado. Focou na criação das unidades de conservação e no Programa Bolsa Floresta. Essas duas políticas estão articuladas entre si e têm um aparato legal com base em legislações federal e estadual. Garcia (2016, p. 192) afirma que com a pesquisa bibliográfica busca-se "ter como escopo do que já foi publicado em relação ao tema de estudo", ampliando a possibilidade de "formular uma nova teoria ou hipótese ou contribuição sobre o assunto". Como lembra Gil (2002, p. 44), a pesquisa bibliográfica é realizada tendo como "base material já elaborado, constituído principalmente de livros e artigos científicos".

$\mathrm{Na}$ fase de busca de estudos, pesquisas e relatórios relacionados ao desenvolvimento dos programas e projetos de serviços ambientais procurou-se identificar potencialidades, oportunidades e limitações na consolidação da unidade de conservação e do Programa Bolsa Floresta.

A pesquisa exploratória buscou maior conhecimento sobre os sistemas de produção existentes em comunidades localizadas na RDS-PP. Esse tipo de pesquisa permitiu "aprimorar hipóteses, validar instrumentos e proporcionar familiaridade" com o objeto (FRANCO; DANTAS, 2017, p. 14846). Ela permite ampliar e melhorar a aprendizagem, como também aprimorar as perguntas relacionadas ao objeto de estudo.

O locus da pesquisa exploratória é o conjunto das comunidades Divino Espírito Santo (Pinheiro), Nossa Senhora do Livramento (Uixi) e São João Batista (Uauaçu), na RDS-PP, situada em Beruri, a $370 \mathrm{~km}$ de Manaus, capital do estado do Amazonas, como mostra a Figura 2. A RDS ocupa uma área de 834.245 ha e é formada por ecossistema alagado de várzea e terra firme. A pesquisa foi desenvolvida em 2015, no âmbito do projeto de Mapeamento de Castanhais Nativos e Caracterização Socioambiental e Econômica de Sistemas de Produção da Castanha-doBrasil na Amazônia (MapCast), com uma amostragem de 30 famílias.

A pesquisa bibliográfica e exploratória é de natureza qualitativa no intuito de obter dados e informações "descritivos sobre pessoas, lugares e processos interativos pelo contato direto do pesquisador com a situação estudada, procurando compreender segundo a perspectiva dos sujeitos, ou seja, dos participantes da situação em estudo" (GODOY, 1995, p. 58).

Portanto, com esses instrumentos, buscamos produzir um texto capaz de evidenciar os avanços e os desafios que envolvem a consolidação, manutenção e conservação dos serviços ambientais e ecossistêmicos no Amazonas.

\section{Resultados e Discussões}

No Amazonas há projetos e programas comunitários, tanto municipais quanto estaduais, relacionados aos serviços ambientais e ecossistêmicos. Esses programas evidenciam o potencial das ações relacionadas aos serviços ambientais e ecossistêmicos como alternativa para conservação e preservação ambiental, como também para garantir a provisão de recursos necessários para manutenção do bem-estar socioeconômico de comunidades rurais. 


\section{Serviços ambientais e ecossistêmicos, conceitos e embasamento legal}

A Lei Federal $n^{0}$ 312/15 define os serviços ambientais como "iniciativas individuais ou coletivas que podem favorecer a manutenção, a recuperação ou a melhoria dos serviços ecossistêmicos" (BRASIL, 2015b). A definição encontrada na lei estabelece um conceito capaz de orientar e programar políticas públicas para esse tema. Entretanto, no âmbito das ciências, há uma grande "complexidade de conceitos envolvidos na avaliação dos benefícios aportados pela dinâmica ecossistêmica à sociedade e ao sistema econômico" (PARRON; GARCIA, 2015, p. 30).

Constanza et al. (1997, p. 253) conceituam serviços ambientais como sendo os "benefícios que as populações humanas obtêm, direta ou indiretamente, das funções de ecossistemas". Nesse estudo conduzido por Constanza et al. (1997) há um conjunto de serviços ambientais que amplia o rol dos já conhecidos e estudados. O estudo inclui dois serviços que já haviam sido indicados por Westman (1977), que são a polinização e o controle biológico.

O trabalho de Daily (1997) definiu serviços ambientais como "as condições e processos através dos quais os ecossistemas naturais e as espécies que os compõem sustentam e satisfazem a vida humana". Nesses serviços está incluída a manutenção da biodiversidade, como a produção de alimento, madeira, combustíveis, produtos farmacêuticos e industriais, entre outros. Para Roma (2014, p. 41-42), a definição de Daily (1997) permite considerar os serviços ecossistêmicos como "os benefícios supridos às sociedades humanas por ecossistemas naturais".

Silva (2011, p.16) afirma que o "meio ambiente historicamente fornece, gratuitamente, uma variedade de bens e serviços de interesse de todos", e que o "conceito de serviços ambientais tornou-se importante para vincular o funcionamento dos ecossistemas com o bem-estar humano. Ele entende que esse vínculo é fundamental para uma ampla gama de contextos de tomada de decisão".

Para Mattos (2013, p. 22), quando o homem "passa a intervir no meio ambiente, seja com baixo impacto, como na agricultura familiar, ou com grande impacto, como no caso do agronegócio ou da indústria, as externalidades se manifestam". Para o autor, as "externalidades negativas são os impactos negativos, as externalidades positivas são os chamados serviços ambientais".

No âmbito das reflexões que estão ocorrendo há décadas, relacionadas ao meio ambiente e aos serviços por ele disponibilizados, há o relatório Avaliação Ecossistêmica do Milênio, organizado pela ONU. Nesse relatório existe um diagnóstico consistente que mostra a perda da biodiversidade e a redução de 24 serviços ecossistêmicos. Nele também consta a definição de serviços ecossistêmicos como "os benefícios que as pessoas obtêm dos ecossistemas" (MILLENNIUM ECOSYSTEM ASSESSMENT, 2005, p. V). Os serviços podem ser classificados em quatro grupos, como podemos observar na Tabela 1.

\footnotetext{
${ }^{4}$ A Lei $^{0}$ 312/15 estabelece conceitos, objetivos e diretrizes da Política Nacional de Pagamento por Serviços Ambientais (PNPSA), cria o Programa Federal de Pagamento por Serviços Ambientais (PFPSA), o Fundo Federal de Pagamento por Serviços Ambientais (FFPSA) e o Cadastro Nacional de Pagamento por Serviços Ambientais (CNPSA), como dispõe sobre os contratos de pagamento por serviços ambientais, e altera as Leis $n^{\circ} 8.001$, de 13 de março de 1990, e Lei $\mathrm{n}^{\circ} 8.666$, de 21 de junho de 1993 (BRASIL, 2015b).
} 
Tabela 1. Categorias de serviços dos ecossistemas.

\begin{tabular}{|c|c|}
\hline Categorias de serviços & Descrição \\
\hline Serviços de provisão & $\begin{array}{l}\text { Produtos obtidos diretamente dos ecossistemas, tais } \\
\text { como alimentos, água doce, lenha, fibras, biomoléculas } \\
\text { (utilizadas como fontes de fármacos) e recursos } \\
\text { genéticos. }\end{array}$ \\
\hline Serviços de regulação & $\begin{array}{l}\text { Benefícios obtidos da regulação de processos } \\
\text { ecossistêmicos, que inclui regulação climática, controle } \\
\text { de doenças, regulação hídrica, purificação da água e } \\
\text { polinização. }\end{array}$ \\
\hline Serviços culturais & $\begin{array}{l}\text { Benefícios imateriais obtidos dos ecossistemas, tais } \\
\text { como espirituais e religiosos, recreação e ecoturismo, } \\
\text { estéticos, de inspiração, senso de lugar e herança } \\
\text { cultural. }\end{array}$ \\
\hline Serviços de suporte & $\begin{array}{l}\text { Necessários para a produção de todos os outros } \\
\text { serviços ecossistêmicos, tais como formação do solo, } \\
\text { ciclagem de nutrientes, produção primária e habitat } \\
\text { para espécies. }\end{array}$ \\
\hline
\end{tabular}

Fonte: Millennium Ecosystem Assessment (2005).

De Groot et al. (2010) abordam a relação dos ecossistemas e o bem-estar humano numa perspectiva histórica desde o período romano. Porém esse tema somente passa a ser debatido a partir de 1970 e a fazer parte das leituras que buscam aprimorar o desenvolvimento econômico.

A leitura dos estudos: "Human population and the global environment" (HOLDREN; EHRLICH, 1974) e "How much are nature's service worth" (WESTMAN, 1977) é fundamental para entender a importância dos serviços ambientais e ecossistêmicos. Esses dois trabalhos colocam em evidência a função do ambiente, os serviços disponibilizados aos seres humanos e a importância da valoração de tais serviços ecossistêmicos, como forma de garantir o bem-estar humano. Os estudos também são pioneiros em apresentar e analisar a importância da temática para a humanidade, e desde então têm-se multiplicado as pesquisas e análises relacionadas aos problemas ambientais e como eles se relacionam com a dinâmica econômica, com o desenvolvimento e o bem-estar da humanidade.

Onishi et al. (2013, p. 7), com base em Imperatriz-Fonseca e Nunes-Silva (2010), mostram que a redução dos ecossistemas tem diminuído em " $35 \%$ os manguezais, $40 \%$ as florestas e 50\% as áreas alagadas; $80 \%$ nos estoques de peixe e $25 \%$ da superfície terrestre devido a áreas cultivadas". Para os autores, no atual cenário, os sistemas naturais “estão se aproximando dos chamados pontos de ruptura ou tipping point, para os quais uma perturbação adicional pode resultar em queda abrupta e irreversível dos benefícios proporcionados”.

Constanza et al. (1997) entendem que a economia da terra ficará paralisada em um cenário de completa supressão dos serviços ecossistêmicos de apoio à vida humana caso se extingam os serviços ambientais. É esse entendimento que permite a conclusão de que os serviços ecossistêmicos possuem valor incalculável. A dificuldade em quantificar os serviços ecossistêmicos pode levar a um reducionismo ou à não incorporação deles nas análises" dos benefícios dos serviços 
ao bem-estar das pessoas ou na avaliação dos impactos negativos para o ambiente e a economia (ANDRADE; ROMEIRO, 2009).

Para Onishi et al. (2013, p. 8), os serviços disponibilizados pelos "ecossistemas ainda não são percebidos pela maior parcela da sociedade como essenciais para a manutenção do bem-estar e da própria sobrevivência dos seres humanos na terra”. Para confirmar a conclusão, os autores citam o caso da região amazônica, onde "pouco se conhece sobre os inúmeros benefícios provisionados pela Floresta Amazônica, além dos tradicionais produtos de origem florestal, explorados".

A ideia de pagamento pelos serviços da natureza recebidos a quem é fiduciário e/ou tem a responsabilidade de conservar esses serviços passa a fazer parte do debate sobre os serviços ambientais. Silva (2011, p. 21), em suas análises, com base em Mayrand e Paquin (2004), define o pagamento de serviços ambientais como sendo o "apoio às externalidades ambientais positivas através da transferência de recursos financeiros dos beneficiários de certos serviços ambientais, para aqueles que prestam esses serviços ou são fiduciários de recursos ambientais”. Esse conceito permite entender que a conservação se torna uma atividade atrativa para gestões e comunidades que têm a missão de sobreviver e cuidar de áreas de proteção.

Gonçalves (2013, p. 31) diz que a disposição do proprietário rural em manter os serviços ambientais gerados em sua unidade pode ser estimulada por compensações, que podem ser "financeiras ou não, para que parte da sociedade realize atividades de proteção e recuperação ambiental, trazendo benefícios para toda a população, ou para uma parcela dela, que até então não oferecia qualquer contrapartida aos primeiros".

Peralta (2014, p. 21), com base em Wunder (2006), afirma que a caracterização dos pagamentos de serviços ambientais parte de alguns pressupostos:

1) Trata-se de um acordo voluntário entre as partes; 2) O objeto da transação é um serviço ambiental claramente definido, ou, por exemplo, o uso sustentável do solo permitindo assegurar o serviço ambiental; 3) Deve existir pelo menos um comprador e um provedor do serviço; e 4) O provedor dos serviços do ecossistema deve assegurar a prestação desses serviços (condicionalidade).

Para Peralta (2014, p. 21), o pagamento dos serviços ambientais é um "incentivo para que aqueles que podem decidir sobre o uso e a conservação de um ecossistema optem por proteger os serviços ambientais, que ele presta ao longo do tempo", o que para o autor "trata-se de uma medida que visa tanto à prevenção do dano ambiental como à restauração do meio ambiente".

\section{Políticas e Programas de Serviços Ambientais e Ecossistêmicos no Amazonas}

Poucos estados no Brasil criaram políticas visando à mitigação dos impactos das mudanças climáticas. O Amazonas está entre os primeiros estados do Brasil a criar a Política Estadual de Mudanças Climáticas, dotando-a de programa como instrumento de consolidação.

O Amazonas foi o primeiro Estado brasileiro a estabelecer uma Política Estadual de Mudanças Climáticas. Em 2007, através da Lei n 3.135/2007, o Estado instituiu a Política Estadual sobre Mudanças Climáticas, Conservação e Desenvolvimento 
Sustentável do Amazonas (PEMC-AM). A política teve base no Decreto nº 26.581/2007 que, além de estabelecer critérios para sua criação, prevê diferentes programas e incentivos para compensação de emissões. Ainda em 2007, foi instituída a Lei Complementar $\mathrm{n}^{\circ}$ 53, que criou o Sistema Estadual de Unidades de Conservação (SEUC), que aliado às diretrizes da PEMC, somou um importante arcabouço legal para gestão dos serviços ambientais em Unidades de Conservação do Estado. Tal contexto permitiu a criação de inciativas como o Programa Bolsa Floresta (PBF), importante política estadual que visa instituir o pagamento por serviços ambientais em comunidades tradicionais, incentivando a proteção e o uso sustentável dos recursos naturais. O Programa foi implementado em 2007 pela Secretaria de Meio Ambiente e Desenvolvimento Sustentável (SDS) e, em 2008, passou a ser executado pela Fundação Amazonas Sustentável - FAS (ALARCON et al., 2008, p. 6).

Entre os programas que resultaram da Política Estadual de Mudanças Climáticas está o Programa Bolsa Floresta. Segundo Viana (2008), esse programa foi concebido na esteira do processo de implementação do Programa Zona Franca Verde, após a criação da Secretaria de Meio Ambiente do Estado do Amazonas, cuja base está na experiência do programa de serviços ambientais da Costa Rica. O autor define o Programa Bolsa Floresta como

[...] uma compensação financeira para os serviços prestados pelas populações tradicionais e indígenas do Amazonas, para a conservação das florestas. Com o Programa Bolsa Floresta estamos reconhecendo que a conservação das florestas é resultado das atitudes das pessoas, especialmente daqueles que vivem nos beiradões e no interior de nossas florestas: os guardiões da floresta. O Programa Bolsa Floresta tem como ponto de partida o termo de compromisso assinado pela FAS e pelas populações que conservam as florestas do Amazonas. As comunidades assumem o compromisso de desmatamento zero (para áreas de floresta primária) e a FAS assume o compromisso de implementar os quatro componentes do Programa Bolsa Floresta. Inicialmente, o Programa esteve direcionado para as populações residentes nas unidades de conservação estaduais. A razão é simples, nessas áreas já existe definida a base legal para os "produtos ambientais" e os "serviços ambientais". Numa segunda etapa, pretende-se alcançar outras áreas do Amazonas (VIANA, 2008, p. 145).

No cenário da existência de um conjunto de iniciativas voltadas para que as comunidades rurais, comunidades tradicionais e agricultores envolvidos entendam a importância do manejo dos recursos naturais e dos ecossistemas e da sua importância para a manutenção e conservação ambiental, o programa Bolsa Floresta insere-se como um "instrumento inovador de grande potencial para promover a conservação e desenvolvimento sustentável na Amazônia (VIANA, 2008, p. 8).

A criação desse arcabouço legal em 2007 possibilitou a evolução das áreas protegidas, criando um período de expansão de unidades de conservação entre os anos de 2009 e 2015 . O conjunto de normas sobre o tema possibilitou a ampliação do território estadual de unidades de conservação (UCs) para 18.808 .342 ha, o que representa 12,06\% da área territorial do Amazonas. Para Rodrigues (2016, p. 40), o período posterior a 2015 "parece indicar o fim de um ciclo de expansão das Unidades de Conservação no Amazonas”, já que desacelerou a criação de novas UCs. 
Tabela 2. Unidades de conservação no estado do Amazonas.

\begin{tabular}{lccc}
\multicolumn{1}{c}{ Áreas protegidas } & Número & Área (ha) & Território Estadual (\%) \\
Unidades de Conservação Federais & 47 & 23.631 .558 & 15.16 \\
Unidades de Conservação Estaduais & 41 & 18.808 .342 & 12.06 \\
Unidades de Conservação Municipais & 23 & 1.853 .012 & 1.19 \\
Terras Indígenas & 176 & 42.205 .013 & 27.06 \\
Total & $\mathbf{2 7 3}$ & $\mathbf{8 4 . 6 4 4 . 0 3 5}$ & $\mathbf{5 5 . 4 7}$
\end{tabular}

Fonte: SDS/CEUC (2013 citado por Bueno, 2013, p. 10).

Para Fraxe et al. (2017, p. 65), as UCs "são constituídas de acordo com as características de cada área, visando à conservação ecossistêmica e reconfigurando as atividades prejudiciais ao funcionamento autopoiético do sistema ambiental". Para a autora, a criação da UC "é uma das estratégias conservacionistas e preservacionistas do estado do Amazonas de mitigação de conflitos territoriais voltados ao uso de recursos naturais".

Fraxe et al. (2017, p. 68) observam uma "simbiose entre as populações tradicionais e o ambiente, entre a lógica e a simbólica do modo de vida tradicional, desconstrói a assertiva de que a presença humana acentua a degradação ambiental".

Relatório do Tribunal de Contas da União (TCU, 2012, p. 20) indica que "o papel de remoção de carbono exercido pelas UCs é tão relevante que pode alterar o panorama de emissão de CO2 de determinado Estado". É o que ocorre, "graças às suas Unidades de Conservação estaduais e federais, nos Estados do Amazonas e do Amapá".

Consta, no relatório do Tribunal de Contas do Estado do Amazonas (TCE, 2013,p.17), que o crescimento das UCs do Amazonas é "reconhecido como exemplo de política sustentável no Brasil por instituições nacionais e também por membros da cooperação internacional (doadores, institutos, bancos de fomento)". Os resultados da implantação dessas unidades são consequência da "visão estratégica do Governo do Estado, que buscou formular instrumentos jurídicos, para garantir um alicerce seguro para a execução de ações específicas e transversais para o fortalecimento da gestão ambiental".

Porém, segundo o tribunal, a continuidade do sucesso da política da UC passa pelas soluções de problemas no que diz respeito à insuficiência de recursos humanos. O TCE diz que há um funcionário para cuidar de $386 \mathrm{~km}^{2}$ nas unidades, enquanto nos Estados Unidos a relação é um funcionário para $21 \mathrm{~km}^{2}$. Além do aspecto da falta de recursos humanos, há fatores a serem resolvidos, como a regularização fundiária, gestão e investimento de recursos, aprimoramento de sistema de controle e fiscalização e outros. No relatório encontramos uma nítida referência à ausência de estrutura da gestão para desenvolver sua missão na unidade. Diz o relatório:

o que se observou durante as visitas de campo nas UCs é que a força destas instituições, onde atuam e no entorno, aparece de forma muito evidente, suplantando inclusive a gestão do CEUC, uma vez que o chefe de unidade conta com poucos recursos para fazer as atividades de monitoramento e, muitas vezes, aproveita "carona" nas atividades das instituições parceiras para fazer uma visita às comunidades e localidades das UCs (TCE, 2013, p. 49). 


\title{
Programa Bolsa Floresta
}

O arcabouço legal aprovado em 2007, Política Estadual de Mudanças Climáticas (Lei ${ }^{\circ}$ 3.135/2007), além de permitir a ampliação da criação de UCs, foi essencial para o desenvolvimento do Programa Bolsa Floresta (PBF). Rodrigues (2016) afirma que:

\begin{abstract}
nesta lei foram definidas as bases legais do Programa Bolsa Floresta e o conceito de produtos e serviços ambientais. Esse marco legal serviu também de base para a criação da Fundação Amazonas Sustentável (FAS) através de um inovador arranjo institucional, em dezembro de 2007. A FAS tem o objetivo de fazer a gestão dos produtos e serviços ambientais das unidades de conservação estaduais e a gestão do programa Bolsa Floresta (VIANA, 2008). O art. 5, inciso II da Política Estadual de Mudança Climática trata sobre o pagamento por serviços e produtos ambientais às comunidades tradicionais pelo uso sustentável dos recursos naturais, conservação, proteção ambiental e incentiva às políticas voluntárias de redução de desmatamento (RODRIGUES, 2016, p. 40).
\end{abstract}

Rodrigues (2016, p. 40) diz que o "Programa Bolsa Floresta (PBF) é considerado o mais relevante instrumento econômico da Política de Mudanças Climáticas do Amazonas, já implantado". O programa visa à "compensação financeira para os serviços prestados pelas populações tradicionais e indígenas do Amazonas: a conservação das florestas” (VIANA, 2008, p. 145).

O arranjo do Programa Bolsa Floresta inclui quatro componentes de concessão dos benefícios. Esses componentes são:

1) Bolsa Renda - Busca a inclusão produtiva para enfrentamento da pobreza e a preservação do meio ambiente ( $\mathrm{R} \$ 350,00$ por família ao ano). Esse benefício está voltado para a geração de renda, a produção sustentável. Porém, para ser elegível, a atividade precisa manter a floresta em pé. Para Fernandes (2016, p. 106), o objetivo é “dinamizar as cadeias produtivas de turismo, artesanato, madeira, borracha, pirarucu, castanha, açaí, óleos vegetais, avicultura, cantinas e pequenos empreendimentos comunitários. O apoio abrange infraestruturas, equipamentos, serviços e capacitações”.

2) Bolsa Floresta Social - Visa melhorar a qualidade de vida com os investimentos direcionados para a "implementação de projetos de infraestrutura comunitária, tais como: construção e reforma de escolas, compra de 'ambulanchas' para atendimentos de emergência, barcos rápidos para transporte público comunitário, rádios, redes de distribuição de água e de energia, etc." (FERNANDES, 2016, p. 107).

3) Bolsa Floresta Familiar (BFF) - Componente de subvenção financeira que é repassada para as mães, no valor de R $\$ 50,00$ por mês, como forma de recompensa por conservarem a floresta. O programa reforça o protagonismo da mulher ao repassar o cartão de débito logo após a participação dela na capacitação sobre mudanças climáticas, serviços ambientais e a assinatura do termo de compromisso e outros procedimentos. "O PBFFamiliar é um importante mecanismo para envolver a população local nas atividades de combate ao desmatamento (VIANA et al., 2013, p. 258)". 
4) Bolsa Floresta Associação (BFA) - Visa fortalecer a organização e o controle social e incentivar a formação de novas lideranças. As "associações recebem um repasse em crédito e/ou em banco, o equivalente a $10 \%$ do total do que é pago ao componente BFF de cada UC. É feito um somatório sobre o número de famílias beneficiárias do componente familiar, em média são R \$ 67,20 por família, sobre o componente associação, num valor médio de R\$30.000,00 por UC ao ano (FERNANDES, 2016, p. 105).

Figura 1. Fluxograma de funcionamento da Fundação Amazonas Sustentável.

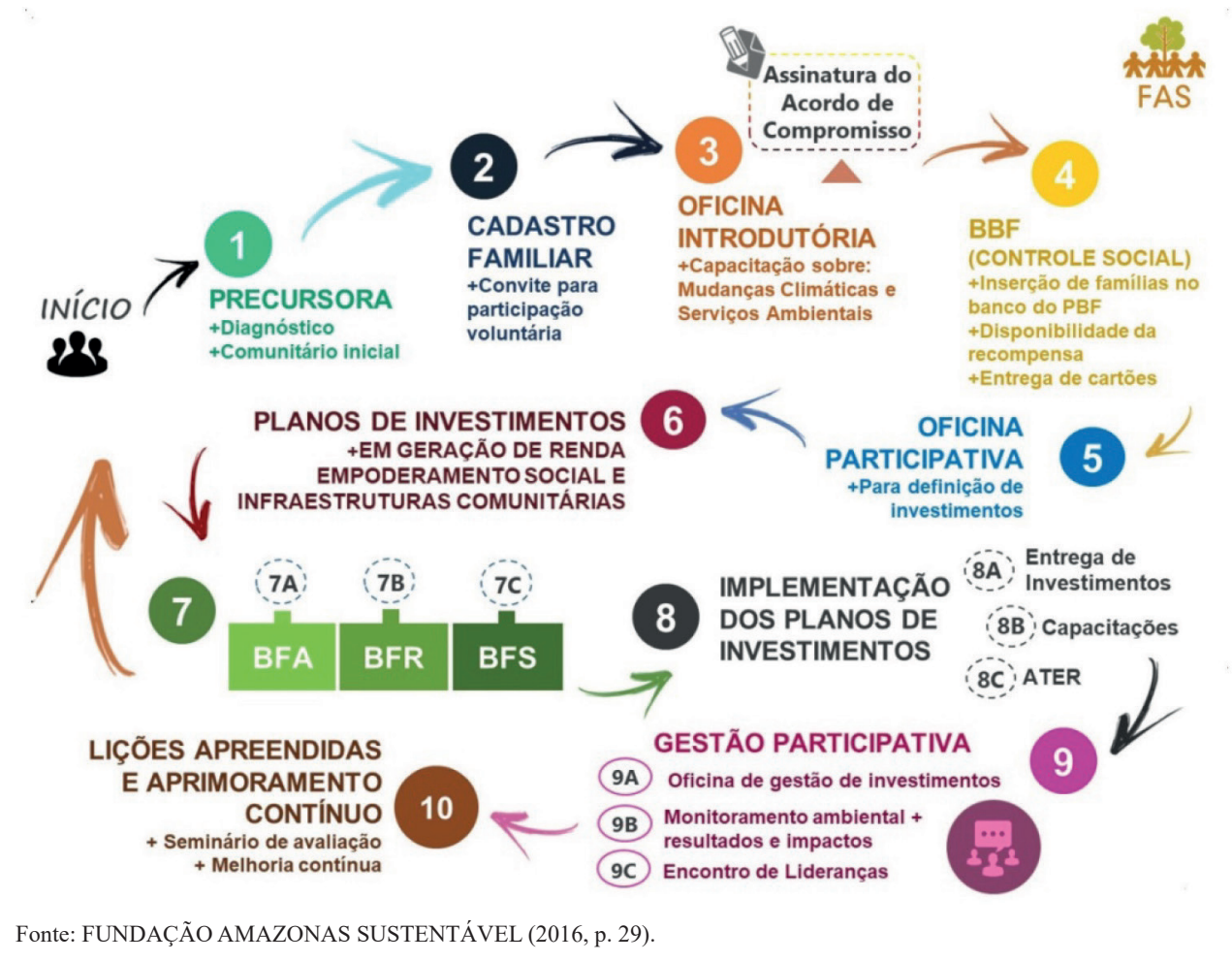

O arranjo organizativo do Programa Bolsa Floresta visa potencializar os indivíduos, a comunidade, a organização social, como também uma cadeia de produção capaz de valorizar os produtos da floresta. Além desses aspectos, chama a atenção a adesão voluntária dos beneficiários e o compromisso que assumem ao participar do programa. Esses compromissos são:

- Cumprir com as regras do plano de uso ou do plano de gestão da reserva.

- Estar associado e adimplente com a associação de moradores da comunidade e da reserva e participar ativamente de suas atividades.

- Manter as roças com tamanho não superior àquele do início do ano do PBF na comunidade, cultivando apenas em áreas de capoeira abertas ou em descanso e de manejo florestal, não avançando em áreas de mata bruta (primária).

- Manter matriculados e frequentando a escola os filhos em idade escolar, caso haja escolas próximas às residências. 
- Fazer aceiro no entorno das áreas de roçado e comunicar à comunidade o dia da queima (FERNANDES, 2016, p. 103).

Os números do Programa Bolsa Floresta dão a dimensão dos resultados do programa. $\mathrm{O}$ número de famílias cadastradas nas 15 unidades de conservação ultrapassa 8.090 famílias ${ }^{5}$, sendo que 7.295 famílias já foram beneficiadas, o que significa 31.988 pessoas participando do programa.

Tabela 3. Famílias e pessoas cadastradas e beneficiadas no Programa Bolsa Floresta.

\begin{tabular}{|c|c|c|c|c|}
\hline $\begin{array}{l}\text { Unidade de } \\
\text { Conservação }\end{array}$ & $\begin{array}{c}\text { Número de famílias } \\
\text { cadastradas }\end{array}$ & $\begin{array}{l}\text { Total de pessoas } \\
\text { cadastradas }\end{array}$ & $\begin{array}{c}\text { Número de pessoas } \\
\text { beneficiadas }\end{array}$ & $\begin{array}{l}\text { Total de pessoas } \\
\text { beneficiadas }\end{array}$ \\
\hline Floresta Maués & 718 & 3.045 & 625 & 2.721 \\
\hline RDS Amanã & 758 & 3.615 & 732 & 3.499 \\
\hline RDS Canumã & 228 & 997 & 224 & 981 \\
\hline RDS Cujubim & 44 & 206 & 23 & 106 \\
\hline RDS Juma & 462 & 1.926 & 417 & 1.763 \\
\hline RDS Mamirauá & 1.937 & 9.083 & 1.705 & 7.995 \\
\hline RDS Piagaçu-Purus & 753 & 3.716 & 688 & 3.421 \\
\hline RDS Rio Amapá & 386 & 1.498 & 325 & 1.343 \\
\hline RDS Rio Madeira & 925 & 3.415 & 881 & 3.265 \\
\hline APA Rio Negro & 333 & 1.292 & 328 & 1.276 \\
\hline RDS Rio Negro & 524 & 1.785 & 483 & 1.663 \\
\hline RDS Uacari & 287 & 1.475 & 261 & 1.335 \\
\hline RDS Uatumã & 352 & 1.191 & 267 & 946 \\
\hline RESEX Catuá-Ipixuna & 220 & 1.081 & 185 & 918 \\
\hline RESEX Rio Gregório & 163 & 805 & 151 & 756 \\
\hline Total & 8.090 & 35.130 & 7.295 & 31.988 \\
\hline
\end{tabular}

Fonte: Fundação Amazonas Sustentável (2011) citado por Viana et al. (2013, p. 265).

Nota: Dados até março de 2012.

Além da participação e do envolvimento das pessoas em processos participativos, a formação e capacitação permitem o aumento da percepção dos extrativistas, transformando-os de simples usuários dos recursos naturais a agentes envolvidos na promoção e conservação da floresta. Dados sistematizados por Viana et al. (2013, p. 263) mostram que "nas áreas onde o PBF está presente, durante a seca de 2010, houve a menor incidência (184) de focos de incêndio por milhão de hectares em relação às UCs federais (393) e estaduais sem o Programa Bolsa Floresta (394) no Amazonas", como pode ser observado na Figura 2.

Os aspectos sociais, ambientais e organizativos dos programas desenvolvidos pelo governo do Amazonas, a partir de 2007, mostram a importância de tais programas e projetos. Porém, há desafios relacionados à dinâmica produtiva das comunidades, como a assistência técnica, as políticas ambientais e de programas e mecanismos efetivos para comercialização de seus produtos.

\footnotetext{
Segundo Viana et al. (2013, p. 265), as famílias cadastradas abrangem inclusive as famílias que estão com documentação pendente para receberem o benefício do PBF-Familiar e serão incluídas no programa assim que entregarem os documentos.
} 
Figura 2. Comparação do número de focos de incêndio no Amazonas (2010).

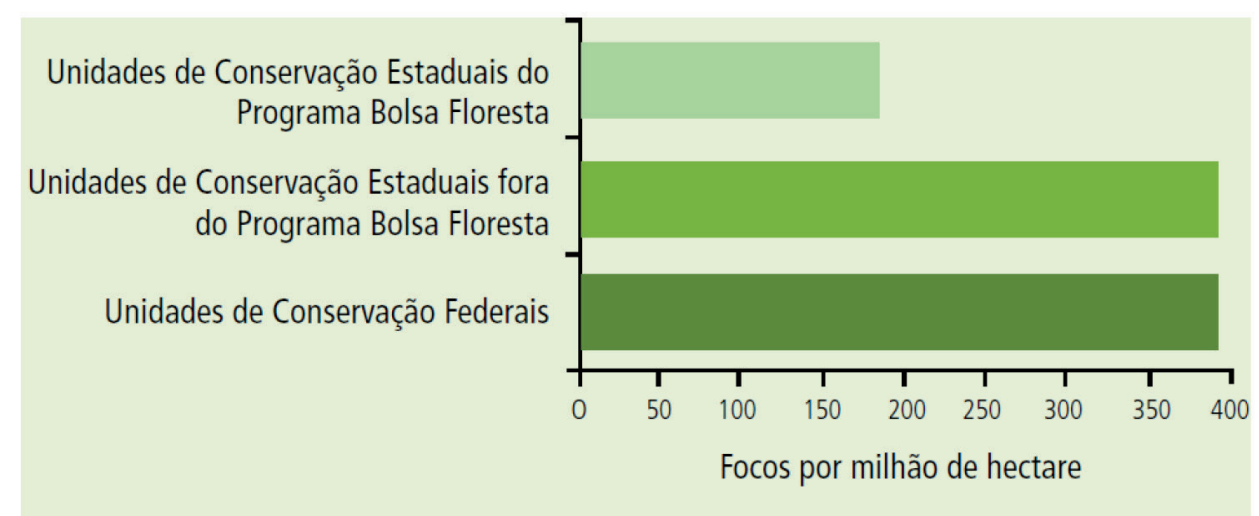

Fonte: Viana et al. (2013, p. 264).

\section{Dinâmica política e socioeconômica em unidade de conservação: elementos para a efe- tivação e manutenção dos serviços ambientais e ecossistêmicos}

Em 2015 foram visitadas comunidades por meio do Projeto Mapeamento de Castanhais Nativos e Caracterização Socioambiental e Econômica de Sistemas de Produção da Castanhado-Brasil na Amazônia (MapCast), da Reserva de Desenvolvimento Sustentável Piagaçu-Purus. Nessas visitas foram contatados e entrevistados 30 extrativistas que desenvolviam a coleta de castanha, a pesca artesanal e o roçado.

Durante a visita às comunidades, em diálogos com os extrativistas, observou-se a dinâmica social e econômica do dia a dia e constataram-se alguns aspectos que fragilizam e impõem desafios para a consolidação e manutenção dos serviços ambientais e ecossistêmicos na unidade de conservação.

O primeiro aspecto é a fragilidade do poder das pessoas e das comunidades. Ela se evidencia no reduzido poder de incidência dos comunitários junto aos órgãos públicos e privados para resolver problemas. Na perspectiva histórica, o reduzido poder dos extrativistas tem origem ligada ao domínio dos patrões, que durante décadas controlaram (e em muitos casos ainda controlam) "por meio do sistema de aviamento, o comércio da castanha e da pesca no Ayapuá" (INSTITUTO PIAGAÇU, 2010, p. 18).

No decorrer da história, a dependência programada pelos patrões criou um extrativista fragilizado, dependente e submisso a uma extensa rede de atravessadores, formada por grandes comerciantes, que aliciam pequenos comerciantes que moram na comunidade, por meio do abastecimento de itens alimentares, gelo e combustível. Esses pequenos comerciantes passam a integrar uma rede de controle da produção de castanha, farinha, peixe e outros produtos, assim como serviços de transporte de produtos e passageiros até a sede do município ${ }^{6}$. Controlam também o acesso e transporte de remédios. A subordinação e o controle ocorrem no repasse de mercadorias, combustível, gelo, passagens e remédios, que, na maioria das vezes, são disponibilizados aos

\footnotetext{
${ }^{6}$ Cabe ressaltar que a comunidade fica a um dia de barco da sede do município, quando a viagem é realizada de recreio, que é um transporte semanal de pessoas e produtos, e de quatro a doze horas, quando realizada com barco de motor de popa, dependendo, é claro, da potência do motor.
} 
extrativistas a preços muito superiores ao de mercado, o que faz com que o extrativista contraia uma dívida que, na ausência de dinheiro em espécie, pode ser paga com a produção extrativa ou agrícola.

Os pequenos comerciantes da comunidade repassam a produção adquirida dos extrativistas ao comerciante maior, dono de recreio (barco), flutuantes e outras estruturas na unidade ou na cidade. Sobre a produção adquirida do extrativista é descontada pelo pequeno comerciante uma porcentagem sobre o valor do preço do produto, que varia de $2 \%$ a $5 \%$, a título de comissão. Sendo que "essa negociação depende também da dívida que os extrativistas comerciantes têm com o patrão. Um importante comprador de castanha, que mantém ampla rede de compradores, é a empresa Mutran, do estado do Pará (SILVA et al., 2017, p. 20).

A dependência ocorre no fabrico da castanha-do-brasil, diante da grande demanda do mercado e da necessidade de renda dos extrativistas, e continua na pesca, principalmente, devido à falta de equipamentos de refrigeração e conservação do peixe, o que torna o gelo nas comunidades de Piaguçu-Purus um artigo de luxo. Esse aspecto acelera a necessidade de o extrativista comercializar a produção imediatamente, o que muitas vezes é feito pelo menor valor oferecido pelo atravessador, que tem mercado certo para os produtos. Como está relatado no plano de gestão da reserva: "Purus é apontado como um dos principais sítios pesqueiros, que abastece de pescado as cidades de Manaus e Manacapuru” (INSTITUTO PIAGAÇU, 2010, p. 45).

No caso da castanha-do-brasil, o município possui uma usina de beneficiamento e comercialização, construída em parceria com o Instituto de Desenvolvimento Agropecuário e Florestal Sustentável do Amazonas (Idam), a Agência de Desenvolvimento Sustentável (ADS), a Agência de Fomento do Estado do Amazonas (Afeam), o Centro Estadual de Unidades de Conservação (CEUC), a Fundação Amazonas Sustentável (FAS) e a Companhia Nacional de Abastecimento (Conab). Essa usina tem colaborado para o fortalecimento da cadeia produtiva da castanha, como também para a melhoria do preço ao extrativista associado a ela.

Essa usina passou por grandes problemas na época da pesquisa, mas está iniciando seu processo de reestruturação, já que sua gestão ficou a cargo da Associação dos Agropecuaristas de Beruri (Assoab). O site da Assoab indica que a associação desenvolve parcerias com empresas de cosméticos e que passou a reorganizar a produção e comercialização da castanha.

Em 2019 a usina foi reformada e tem capacidade de processar $200 \mathrm{t}$ de castanha. Essa reforma elevou em $43 \%$ a capacidade produtiva da usina. Na inauguração, em entrevista ao Jornal Em Tempo, a gestora da usina informou que 344 famílias e 45 comunidades da Piagaçu-Purus, das Terras Indígenas Itixi Mitari, Lago do Ayapuá e na sede do município de Beruri, são beneficiadas pelo trabalho da usina.

A usina é uma alternativa à busca de autonomia da comunidade, porém há grande quantidade de castanha-do-brasil sendo escoada pelos atravessadores, principalmente para Mutran, e outra usina localizada no oeste paraense. Estima-se que 200 t da amêndoa beneficiada, sem casca, necessitam de aproximadamente $350 \mathrm{t}$ de fruto com casca ${ }^{7}$. Considerando que o município produziu 1.200 t em 2018, que a capacidade de processamento da usina é de 350 t, que a maior

Estimativa baseada em Tomasi (2016, p. 9) mostra que "uma lata de castanha in natura de $10 \mathrm{~kg}$, rende $3 \mathrm{~kg}$ de amêndoa de castanha". 
parte da produção está na RDS do Piagaçu-Purus é possível concluir que os atravessadores ainda controlam 850 t, o que equivale a $70 \%$ do total da produção.

Em 2011 havia 753 famílias cadastradas e com potencial de inclusão no Programa Bolsa Floresta na RDS Piagaçu-Purus. Considerando que, de acordo com a gestora da usina, somente 344 famílias com potencial de chegar a 463 famílias, é possível deduzir que dois terços dos extrativistas estão sujeitos a ação dos atravessadores e subordinação a eles.

O domínio da produção de castanha, de peixe, de farinha e outros produtos dos extrativistas, como também o controle de transporte, do combustível, alimentos e remédios, tem impacto profundo no controle da vida diária e dos afazeres dos extrativistas. Nesse sentido, o extrativista é impedido de tornar-se sujeito ativo diante do poder organizado em rede, que domina a todos, em diversos níveis. Nesse sentido, um dos desafios para efetivar as políticas de serviços ambientais e ecossistêmicos é a formação de um extrativista consciente, o que implica ser capaz de assumir o papel de sujeito, com habilidade de fazer e refazer as condições de existência (FREIRE, 1980), ou seja, como a "categoria sujeito confere protagonismo e ativismo aos indivíduos e grupos sociais, transformando-os de atores sociais, políticos e culturais, em agentes conscientes de seu tempo, de sua história, de sua identidade, de seu papel como ser humano, político, social" (GOHN, 2004, p. 18).

O segundo aspecto que está vinculado à necessidade de construção de um sujeito capaz de garantir a manutenção e conservação dos serviços ambientais e ecossistêmicos é a consolidação de um sistema produtivo, eficiente, visando à segurança alimentar e à geração de renda. Tal perspectiva pode ser observada na pesquisa realizada nas comunidades do Piagaçu-Purus. A pesquisa mostrou que há grande diversidade de fontes de renda, porém a maior parte dela é oriunda da pesca, do extrativismo vegetal (castanha, principalmente) e roçado.

$\mathrm{Na}$ lista das atividades produtivas estão a coleta de castanha e açaí, que são produtos extrativos, e os plantios de mandioca e banana, cuja produção é comercializada em pequenas quantidades de acordo com a demanda e possiblidade de comercialização, ou seja, uma ou duas sacas de farinha e um ou dois cachos de banana por semana.

Os sistemas produtivos são tradicionais e desenvolvidos com instrumentos rudimentares, que não permitem uma produtividade de trabalho razoável. Demanda muito esforço físico. Há, entre os extrativistas pesquisados, uma área média de 1,2 ha de roçado por família, com produtividade de mandioca de 6,3 toneladas por hectare, o que significa uma produtividade $47 \%$ menor do que a média de produção estadual, que é de 12 toneladas por hectare.

Um elemento que interfere na conservação e manutenção dos serviços ambientais e ecossistêmicos é a necessidade de aumentar a produtividade do trabalho e a renda. Para isso é necessário construir um conhecimento e uma tecnologia para os sistemas que contemplem a lógica do conhecimento tradicional, da conservação da floresta, mas que associem as tecnologias geradas pela pesquisa. Aqui faz-se menção a todas as formas sustentáveis de melhoria da produção e da redução da penosidade do trabalho. Isso não significa dizer que se introduzam insumos químicos externos ao ambiente, o que aumentaria a dependência dos extrativistas aos atravessadores. O que se propõe é a introdução de práticas de plantio e de manejo que valorize a biodiversidade. 
Um dos exemplos é a técnica de produção da mandioca "Roça sem fogo" e a observação e implementação do trio da produtividade. Segundo Modesto Júnior e Alves (2016, p. 83), a técnica da roça sem fogo busca o

"retorno econômico dos recursos naturais existentes na vegetação de capoeira por meio da lenha, carvão, caibros para construção civil, sementes, óleos, moirões para cercas, plantas ornamentais, artefatos para artesanatos e outros, deixando-se na área as espécies de importância econômica, como fruteiras, essências florestais, espécies melíferas, medicinais, oleíferas e outras, num espaçamento mínimo de $10 \mathrm{~m}$ uma das outras, para evitar o sombreamento da mandioca".

Além da tecnologia de produção de mandioca na técnica roça sem fogo, há também o trio da produtividade, que consiste: na seleção e corte reto de manivas-semente; plantio no espaçamento de 1 metro por 1 metro; controle de plantas daninhas durante os 150 dias após o plantio da mandioca, por ser o período crítico da cultura, que é a época de formação das raízes (ALVES et al., 2008).

É evidente que há muitas técnicas e práticas de plantio e manejo. Citamos alguns exemplos de tecnologias simples com o objetivo de exemplificar o que pode ser inovado e que pode trazer benefícios aos serviços ambientais, com redução de emissões de gases nocivos ao meio ambiente e de baixo custo.

É importante a melhoria da produção nos pomares das famílias extrativistas, o que poderia ser viabilizado com ações de incentivo à implementação de sistemas agroflorestais (SAFs). Há diversos modelos de sistemas com viabilidade técnica, social, econômica e ambiental comprovadas utilizando frutíferas nativas como o cacau, açaí e tantas outras, aumentando a disponibilidade de frutas em ambiente da RDS-PP, sendo que isso "pode contribuir diretamente para a manutenção dos serviços ambientais e ecossistêmicos e contribuir para ampliação do bem-estar familiar e comunitário, bem como a geração de renda e segurança alimentar dos extrativistas" (BRASIL, 2014).

Ressalta-se que as políticas de saúde, educação, transporte, moradia e outras são essenciais para as comunidades. Políticas como a de educação precisam ser articuladas com o sistema de produção, com a inclusão de disciplinas relacionadas a adoção de práticas agrícolas, planejamento e gerenciamento das unidades produtivas são importantes para a transformação dos extrativistas em agentes garantidores dos serviços ambientais e ecossistêmicos.

Os programas de serviços ambientais cujas políticas foram assumidas pelo governo estadual a partir de 2007, com ações eficazes de criação de unidades de conservação e o apoio do Programa Bolsa Floresta, entre outros, desenvolvidos com o apoio de organizações não governamentais e comunidades, precisam ser potencializados. Precisam vislumbrar no horizonte a liberdade, entendida por Sen (2010, p. 26) como a conquistada "com oportunidades sociais adequadas, os indivíduos podem efetivamente moldar seu próprio destino e ajudar uns aos outros". Essas oportunidades precisam contribuir para a constituição de sujeitos ativos e fortalecer sistemas organizativos e produtivos eficientes, capazes de ser o suporte para a manutenção e conservação dos serviços ambientais e ecossistêmicos. 


\section{Considerações Finais}

O estado do Amazonas criou as RDAs, colocando grandes territórios sob a proteção do estado, compartilhando a gestão dessas unidades com organizações da sociedade civil e com as comunidades de moradores dessas áreas. Para dar aporte a essa política, ele criou programas de compensação financeira aos agricultores/extrativistas, sendo que a contrapartida é a preservação ambiental. As comunidades, entretanto, podem continuar usufruindo dos serviços ambientais, preservando o modo de vida e o ambiente.

A pesquisa mostrou que os programas de serviços ambientais e ecossistêmicos, com a criação das UCs e do Programa Bolsa Floresta, foram importantes para a conservação e manutenção dos recursos naturais. Esses programas, no entanto, precisam estar acompanhados de outras políticas públicas de apoio efetivas, que contribuam para a superação das necessidades socioeconômicas das comunidades. A pesquisa sinalizou que, além de ações voltadas a manter os serviços ambientais, são necessárias ações multidisciplinares voltadas a efetivar o empoderamento dos extrativistas, transformando-os em sujeitos sociopolíticos nos parâmetros definidos por Paulo Freire $(1979,1980,2017)$. São necessários avanços no sistema de produção, aportando tecnologias e inovações sustentáveis, contribuindo para o aumento da produtividade dos sistemas, para a melhoria da produtividade do trabalho e reduzindo o impacto sobre o ecossistema, garantindo assim a produção para o autoconsumo, segurança alimentar e geração de renda.

A política de criação dessas unidades, que garante às comunidades e famílias a posse da terra e a manutenção do modo de vida das pessoas tendo como contrapartida a preservação, limita a expansão da área a ser explorada, mas por outro lado garante o direito de usufruir dos serviços ambientais e de intensificar a produção nas áreas de roçados existentes.

O ato político de criação do programa e política é positivo porque deriva da preocupação com a preservação do ambiente, ao mesmo tempo impõe uma "tutela" à conduta dos moradores das comunidades no que diz respeito aos limites do roçado e na liberdade de circulação de pessoas nas comunidades. A política que garante a posse da terra e o programa Bolsa Floresta, por si só, tem alcance limitado no sentido de poder oportunizar uma vida melhor aos extrativistas, a suas famílias e aos jovens, a fim de que permaneçam em suas comunidades, no meio rural.

A política e os programas têm alcance limitado para promover ações de educação, de empoderamento para que as pessoas e as comunidades se tornem sujeitos capazes de gerir suas vidas, gerir o espaço territorial, definindo os rumos para as comunidades, sem a tutela de instituições da sociedade civil ou do estado.

Por fim, manter um modo de vida não significa que as populações devam viver em condições socioeconômicas precárias como seus ancestrais. Existem sonhos, aspirações, necessidade de estruturas e serviços básicos mínimos que possibilitem uma qualidade de vida melhor. Os jovens e os demais têm sonhos, quando não conseguem materializá-los na comunidade e na família, vão para as cidades. Nesse sentido, a disponibilização de serviços básicos, como energia elétrica, internet, serviços de saúde, educação, junto com a introdução de tecnologias que promovam ganhos nos sistemas de produção, melhorando a renda, a segurança alimentar e reduzam a 
penosidade do trabalho, integrados com os serviços ambientais, talvez consigam contribuir mais para a preservação ambiental, tornando a comunidade um lugar bom para se viver.

\section{Referências}

ALARCON, C.; GOULART, I.; CENAMO, M. Desafios e oportunidade para implementação da Lei Estadual de Serviços Ambientais do Amazonas: 180 dias da lei. Manaus: Idesam: Fundação Moore, 2008 .

ALVES, R. N. B.; MODESTO JÚNIOR, M. de S.; ANDRADE, A. C. da S. O trio da produtividade na cultura da mandioca: estudo de caso de adoção de tecnologias na região no Baixo Tocantins, Estado do Pará. In: CONGRESSO DA ASSOCIAÇÃO BRASILEIRA DAS INSTITUIÇÕES DE PESQUISA TECNOLÓGICA, 2008, Campina Grande. Os desníveis regionais e a inovação no Brasil: os desafios para as instituições de pesquisa tecnológica. Brasília, DF: ABIPTI, 2008.

ANDRADE, D. C.; ROMEIRO, A. R. Serviços ecossistêmicos e sua importância para o sistema econômico e o bem-estar humano. Campinas: UNICAMP, 2009. 44 p. (Texto para Discussão, n. 155).

BRASIL. Lei $n^{0} 3.135 / 2007$. Institui a Política Estadual sobre Mudanças Climáticas, Conservação Ambiental e Desenvolvimento Sustentável do Amazonas, e estabelece outras providências. Diário Oficial Eletrônico do Estado do Amazonas, Manaus, n. 31.228, 22 nov. 2007. (Texto consolidado reproduzido no Diário Oficial, n. 31.233, 29 nov. 2007)

BRASIL. Ministério da Agricultura, Pecuária e Abastecimento. Implantação do cacaueiro em sistemas agroflorestais. Brasília, DF, 2014. 76 p.

BRASIL. Projeto de Lei $\mathbf{n}^{\mathbf{0}}$ 312, de 10 de fevereiro de 2015. Institui a Política Nacional de Pagamento por Serviços Ambientais e dá outras providências. Brasília, DF, 2015 b.

BUENO, C. R. Potencial de exploração dos produtos de origem extrativista - presente e futuro. 27 slides. Material apresentado no evento Diálogo Público: A Governança das Unidades de Conservação no Bioma Amazônia do Tribunal de Contas da União - TCU, 2013.

COSTANZA, R.; D’ARGE, R.; GROOT, R. de; FARBERK, S.; GRASSO, M.; HANNON, B.; LIMBURG, K.; NAEEM, S.; O’NEILL, R. V.; PARUELO, J.; RASKIN, R. G.; SUTTON, P.; VAN DEN BELT, M. The value of the world's ecosystem services and natural capital. Nature, v. 387, p. 253-260, 1997.

DAILY, G. C. Nature's services: Societal Dependence on Natural Ecosystems. Washington: Island Press, 1997.

FERNANDES, T. K. Monitoramento e avaliação de programas de desenvolvimento sustentável: análise de experiências de organizações não governamentais. 2016. Dissertação (Mestrado em Desenvolvimento Sustentável) - Universidade de Brasília, Brasília, DF.

FRANCO, M. V. A.; DANTAS, O. M. A. N. A. Pesquisa exploratória: aplicando instrumentos de geração de dados-observação, questionário e entrevista. In: EDUCERE-CONGRESSO NACIONAL DE EDUCAÇÃO, 8., 2017, Curitiba. Anais... Curitiba: PUCPR, 2017.

FRAXE, T. de J. P.; REZENDE, M. G. G.; MACEDO, C. de A.; WITKOSKI, A. C. Áreas protegidas no Amazonas: conservação e sustentabilidade como preceitos ambientais indissociáveis. Revista Amazônica de Ensino de Ciências, v. 10, n. 21, p. 63-71, 2017.

FREIRE, P. Conscientização - teoria e prática da libertação. Uma introdução ao pensamento de Paulo Freire. São Paulo: Editora Moraes, 1980. 
FREIRE, P. Educação como prática da liberdade. Rio de Janeiro: Paz e Terra, 1979.

FREIRE, P. Pedagogia do oprimido. Rio de Janeiro: Paz e Terra, 2017.

FUNDAÇÃO AMAZONAS SUSTENTÁVEL. Relatório de atividades 2015. Manaus, 2016. v. 8.

GARCIA, E. Pesquisa bibliográfica versus revisão bibliográfica - uma discussão necessária. Revista Línguas \& Letras, v. 17, n. 35, 2016.

GIL, A. C. Como elaborar projetos de pesquisa. 4. ed. São Paulo: Atlas, 2002.

GODOY, A. S. Introdução à pesquisa qualitativa e suas possibilidades. RAE - Revista de Administração de Empresas, v. 35, n. 3, p. 21, 1995.

GOHN, M. da G. Paulo Freire e a formação de sujeitos sociopolíticos. In: FÓRUM INTERNACIONAL PAULO FREIRE, 4., 2004. Anais... Porto: Universidade do Porto: Instituto Paulo Freire, 2004.

GONÇALVES, H. Pagamentos por serviços ambientais segundo a ótica da comunidade envolvida - o caso do projeto "Conservador das Águas", Extrema/MG. 2013. Dissertação (Mestrado em Ecologia Aplicada) - Escola Superior de Agricultura "Luiz de Queiroz", Centro de Energia Nuclear na Agricultura, Piracicaba.

GROOT, R. de; FISHER, B.; CHRISTIE, M. Integrating the ecological and economic dimensions in biodiversity and ecosystem service valuation (Chapter 1). In: KUMAR, P. (Ed.). The economics of ecosystems and biodiversity: ecological and economic foundations. London: Earthscan, 2010.

HOLDREN, J.; EHRLICH, P. R. Human population and the global environment. American Scientist, v. 62, n. 3, p. 282-292, 1974.

IMPERATRIZ-FONSECA, V. L.; NUNES-SILVA, P. As abelhas, os serviços ecossistêmicos e o Código Florestal Brasileiro. Biota Neotropica, v. 10, n. 4, 2010. Disponível em: https://www.scielo.br/pdf/bn/ v10n4/08.pdf. Acesso em: 30 fev. 2020.

INSTITUTO PIAGAÇU. Plano de gestão da Reserva de Desenvolvimento Sustentável PiagaçuPurus. v. 1: versão para consulta pública: Beruri, Anori, Tapauá e Coari. Manaus, 2010.

MAYRAND, K.; PAQUIN, M. Payments for environmental services: a survey and assessment of current schemes. Montreal: Unisfera International Centre for the Commission of Environmental Cooperation of North America, 2004.

MATTOS, L. Economia do meio ambiente e serviços ambientais. In: FASE - Solidariedade e Educação Núcleo Justiça Ambiental e Direitos. Visões alternativas aos serviços ambientais. Rio de Janeiro, 2013.

MILLNNIUM ECOSYSTEM ASSESSMENT. Ecosystems and Human Well-Being: synthesis. Washington: Island Press, 2005. 137 p.

MODESTO JÚNIOR, M. de S.; ALVES, R. N. B. Produção de mandioca em roça sem fogo e trio da produtividade. In: MODESTO JUNIOR, M. de S.; ALVES, R. N. B. (Ed.). Cultura da mandioca: aspectos socioeconômicos, melhoramento genético, sistemas de cultivo, manejo de pragas e doenças e agroindústria. Brasília, DF: Embrapa, 2016.

ONISHI, C. M.; VAZOLLER, R. F.; REYDON, B. P. Pagamento por serviços ambientais: benefícios locais e globais. Revista DAE, n. 192, 2013. 
PARRON, L. M.; GARCIA, J. R. Serviços ambientais: conceitos, classificação, indicadores e aspectos correlatos. In: PARRON, L. M.; GARCIA, J. R.; OLIVEIRA, E. B. de; BROWN, G. G.; PRADO, R. B. (Ed.). Serviço ambiental em sistemas agrícolas e florestais do Bioma Mata Atlântica. Brasília, DF: Embrapa, 2015.

PERALTA, C. E. O pagamento por serviços ambientais como instrumento para orientar a sustentabilidade ambiental. A experiência da Costa Rica. In: LAVRATTI, P.; TEJEIRO, G. (Org.). Direito e mudanças climáticas: pagamento por serviços ambientais: experiências locais e latino-americanas. São Paulo: Instituto o Direito por um Planeta Verde, 2014.

RODRIGUES, F. F. A. (Org). Amazonas 2000-2013. São Paulo: Editora Fundação Perseu Abramo, 2016.

ROMA, J. C. Biodiversidade e serviços ecossistêmicos: uma agenda positiva para o desenvolvimento sustentável. In: MONASTERIO, L. M.; NERI, M. C.; SOARES, S. S. D. Brasil em desenvolvimento 2014 : estado, planejamento e políticas. Brasília, DF: Ipea, 2014.

SEN, A. Desenvolvimento como liberdade. São Paulo: Companhia das Letras, 2010.

SILVA, L. de J. de S.; MENEGHETTI, G. A.; PINHEIRO, J. O. C.; CARNEIRO, E. de F.; SILVA, K. E. da; BRITO, V. F. S. de; MORENO, A. A. Castanha-do-Brasil: aspectos socioeconômicos nas comunidades da RDS Piagaçu-Purus, município de Anori, AM. Manaus: Embrapa Amazônia Ocidental, 2017. 35 p. (Embrapa Amazônia Ocidental. Documentos, 135). Disponível em: http://ainfo.cnptia.embrapa.br/digital/ bitstream/item/175345/1/Documentos135.pdf. Acesso em: 30 jul. 2020.

SILVA, W. da C. Viabilidade econômica do pagamento por serviços ambientais no Estado do Amapá utilizando análise de risco. 2011. 106 f. Dissertação (Mestrado) - Programa de Pós-Graduação em Direito Ambiental e Políticas Públicas, Universidade Federal do Amapá, Macapá.

TOMASI, A. Cadeia de valor da castanha do Brasil no município de Lábrea/AM. Brasília, DF: Instituto Internacional de Educação do Brasil, 2016.

TRIBUNAL DE CONTAS DA UNIÃO - TCU. Auditoria operacional. Governança das unidades de conservação do bioma Amazônia. Brasília, DF, 2012.

TRIBUNAL DE CONTAS DO ESTADO DO AMAZONAS - TCE. Relatório conclusivo de Auditoria Operacional e Ambiental em Unidades de Conservação Estaduais do Amazonas. Manaus, 2013.

VIANA, V. M. Bolsa Floresta: um instrumento inovador para a promoção da saúde em comunidades tradicionais na Amazônia. Estudos Avançados, v. 22, n. 64, p. 143-153, 2008.

VIANA, V.; TEZZA, J.; SALVIATI, V.; RIBENBOIM, G.; MEGID, T.; SANTOS, C. dos. Programa bolsa floresta no Estado do Amazonas. In: PAGIOLA, S.; GLEHN, H. C. Von; TAFFARELLO, D. (Org.). Experiências de pagamentos por serviços ambientais no Brasil. São Paulo: SMA/CBRN, 2013.

WESTMAN, W. E. How much are nature's services worth? Science, v. 197, n. 4307, p. 960-964, 1977.

WUNDER, S. Pagos por servicios ambientales: principios básicos esenciales. CIFOR Occasional Paper, n. 42(s), 2006. 